\title{
Revisiting the Side Crushing Test Using the Three-Point Bending Test for the Strength Measurement of Catalyst Supports
}

\author{
D. Staub ${ }^{1,2}$, S. Meille ${ }^{2}$, V. Le Corre ${ }^{1}$, J. Chevalier ${ }^{2}$ and L. Rouleau ${ }^{1 *}$ \\ ${ }^{1}$ IFP Energies nouvelles, Rond-point de l'échangeur de Solaize, 69360 Solaize - France \\ 2 INSA-LYON, MATEIS - CNRS UMR 5510, 69621 Villeurbanne - France \\ e-mail: deborah.staub@ifpen.fr - sylvain.meille@insa-lyon.fr - vincent.le-corre@ifpen.fr - jerome.chevalier@insa-lyon.fr \\ loic.rouleau@ifpen.fr \\ * Corresponding author.
}

\begin{abstract}
The side crushing test is commonly used to characterize the mechanical strength of catalyst supports. However its interpretation is complex for cylindrical supports due to their irregular geometry and the various fracture modes induced. A better analysis of the crushing test, altogether with a comparison of the results obtained with the three-Point Bending test (3PB) and an analysis of the defects present within the supports, provide a better interpretation of their crushing strength data. Experimental results show that two different fracture modes appear during the crushing test - one under bending configuration and one under crushing configuration - inducing a large scatter of the data. Moreover, a comparison with the 3PB test shows that the strength measured in crushing is lower and the scatter of the data is larger than the ones obtained in bending. This is a consequence of a Weibull size effect and of the presence of macro-defects within one type of the tested supports. It is concluded that an analysis of the fracture modes activated during crushing has to be carried out to obtain a correct distribution of the strength data. The presence of macro-defects within the microstructure of the supports decreases drastically the crushing strength, while their influence on the bending strength is more limited.
\end{abstract}

Résumé - Test d'écrasement grain à grain revisité à l'aide du test de flexion trois points pour la mesure de la résistance des supports de catalyseurs - Le test d'écrasement grain à grain est couramment utilisé pour caractériser la résistance mécanique des supports de catalyseurs. Cependant, son interprétation est complexe pour les supports cylindriques du fait de leur géométrie irrégulière et des différents modes de rupture qu'elle induit. Une analyse détaillée du test d'écrasement, ainsi qu'une comparaison avec les résultats obtenus par le test de flexion trois points et une analyse des défauts présents au sein des supports, permettent d'interpréter plus précisément les données de résistance à l'écrasement obtenues. Les résultats expérimentaux montrent la coexistence de deux différents modes de rupture lors du test d'écrasement - un premier apparaissant sous configuration de flexion et un second apparaissant sous configuration de compression diamétrale - menant à une large dispersion des valeurs. De plus, la comparaison avec le test de flexion trois points montre, d'une part, que la résistance mesurée en écrasement est plus faible et, d'autre part, que la dispersion des données est plus grande que celles obtenues en flexion. Ces caractéristiques résultent d'un effet de taille ainsi que de la présence de macro-défauts au sein d'un des types de supports testés. 
En conclusion, il apparaît qu'une analyse des modes de rupture activés lors de l'essai d'écrasement doit être menée afin d'obtenir une distribution correcte des valeurs de résistance. La présence de macro-défauts au sein de la microstructure des supports réduit considérablement leur résistance à l'écrasement, alors qu'ils ont une influence plus limitée sur la résistance en flexion.

\section{LIST OF SYMBOLS}

\begin{tabular}{|c|c|}
\hline $\mathrm{BC}$ & Bending Configuration \\
\hline $\mathrm{CC}$ & Crushing Configuration \\
\hline$d$ & Sample diameter $(\mathrm{m})$ \\
\hline$F$ & Fracture load $(\mathrm{N})$ \\
\hline$i$ & Integration point \\
\hline$l$ & Sample length $(\mathrm{m})$ \\
\hline$L$ & Span between load points in bending (m) \\
\hline$m$ & Weibull modulus \\
\hline$P$ & Probability of failure \\
\hline$R^{2}$ & Correlation coefficient \\
\hline SEM & Scanning Electron Microscopy \\
\hline$V$ & Sample volume $\left(\mathrm{m}^{3}\right)$ \\
\hline$V_{0}$ & Reference volume $\left(\mathrm{m}^{3}\right)$ \\
\hline$V_{e f f}$ & $\begin{array}{l}\text { Effective volume subjected to maximum tensile } \\
\text { stress }\left(\mathrm{m}^{3}\right)\end{array}$ \\
\hline$V_{i}$ & $\begin{array}{l}\text { Volume associated with an integration point } i \\
\left(\mathrm{~m}^{3}\right)\end{array}$ \\
\hline$\sigma$ & Stress $(\mathrm{Pa})$ \\
\hline$\sigma_{0}$ & Characteristic strength $(\mathrm{Pa})$ \\
\hline$\sigma_{I}^{i}$ & $\begin{array}{l}\text { Maximum positive principal stress at an inte- } \\
\text { gration point } i(\mathrm{~Pa})\end{array}$ \\
\hline$\sigma_{\max }$ & Maximum tensile stress $(\mathrm{Pa})$ \\
\hline
\end{tabular}

\section{INTRODUCTION}

In fixed bed reactors for oil refinery, solid catalysts can fracture during their loading into the reactor, or when operating due to the weight of the catalysts bed. This mechanical fracture can result in the formation of fragments and fines that may cause various problems: uneven distribution of fluid flow, blockage, large pressure drops across the reactor, variations in heat flux, downstream fouling. In some cases, it may also cause environmental problems because of the release of fines in the atmosphere (Beaver, 1975; Wu et al., 2003, 2007). Therefore, the mechanical strength of catalyst supports is important to ensure reliable performance of a fixed bed reactor (Andrew, 1981; Denny and Twigg, 1980; Gallei and Schwab, 1999). Although most of the investigations on catalysis carrier have concentrated on the improvement of catalytic properties, with a general trend of increasing the total porous volume, this increase in porosity is at the expense of the mechanical strength of the supports. Thus, a better understanding of the mechanical behavior of the supports is needed to be able to optimize their strength while keeping an important porous volume.

Solid catalysts are generally made of mixed oxides such as transition aluminas, and are fabricated as tablets, extrudates or granules. These materials exhibit a brittle fracture when subjected to tensile stresses (Richardson, 1989; Fulton, 1986; Li et al., 1989, 1999, 2004). According to Griffith theory, the brittle fracture of materials originates from tensile stress concentration at the edge of an existing critical flaw (Griffith, 1921; Kanninen and Popelar, 1985). Catalyst supports are highly porous and contain randomized defects like large pores, impurities or cracks. Variations of size, shape and orientation of the flaws, as well as their location in the support, result in a large scatter of the mechanical strength. Therefore, a statistical approach has to be carried out to analyze the strength of catalyst supports.

Currently, the most common test performed in industry to characterize mechanical strength of the supports is the side crushing strength test. It consists in a diametral compression of a cylindrical sample between two platens and allows an indirect measurement of its tensile strength, called crushing strength. This test, also known as the Brazilian test, has been accepted as a standard method since it can be easily set up and allows a quick measurement of the crushing strength of a sample considering a tensile fracture (ASTM D4179-01, 2001; ASTM D6175-03, 2003; National Standard of China GB-3635-83, 1983; National Standard of China GB$10505.1-89,1989)$. However, although this test is well suited to spherical supports and tablets, it has been shown that it is questionable for cylindrical extruded supports because of their irregular geometry. A wide distribution in length and distortion in the axial direction is indeed noted after the preparation of the samples (extrusion followed by drying and calcination). These irregularities induce a non-repeatability of the stress distribution during the test and a very large scatter of strength values, leading to a much complex interpretation of the crushing data. Instead of the crushing test, Li et al. (2000) studied the three-point bending test, which has been widely used to measure the strength of 
brittle materials. They showed it was more adapted for the mechanical characterization of extruded supports because their fracture is always favored under the upper load point and the specimen distortion has a limited influence on the results. Yet, the crushing test is widely used in industry and cannot be easily discarded. Thus, a proper analysis of the data for cylindrical supports is still missing to be able to rightfully support or reject its use to characterize this type of pellets.

The objective of this study is to improve the analysis of the side crushing strength test for cylindrical extrudates in order to provide a better interpretation of the data, and to compare the results with those obtained with Three-Point Bending test (3PB). An analysis of the defects present within the supports, using X-Ray tomography and Scanning Electron Microscopy (SEM), is also carried out to help interpreting the measured strength.

\section{MATERIALS AND METHODS}

\subsection{Materials - Catalysts Samples}

The samples are cylindrical extrudates made of highly porous gamma alumina. They are typically prepared by shaping of boehmite (Euzen et al., 2002) synthesized by IFP Energies nouvelles (Solaize, France) from precipitation of aluminum salts, washing with dionized water and drying. Boehmite powder is kneaded by acid solution (peptization) and with basic solution (neutralization). The paste is then extruded through a die with a unique cylindrical hole, dried and calcined. The sample final diameter is $1.4 \mathrm{~mm}$ and the final length varies from 3 to $20 \mathrm{~mm}$ depending on the test used.

Two different types of materials are studied. One exhibits a monomodal porosity with only mesopores, hereafter labeled "monomodal"; the other contains a bimodal porosity with mesopores and macropores, hereafter labeled "bimodal". Their physical properties are presented in Table 1, as determined by mercury intrusion porosimetry and nitrogen physisorption (BET specific surface area).

\subsection{Observation of Sample Structure}

\subsubsection{X-Ray Microtomography}

$3 \mathrm{D}$ computed tomography is performed on both types of catalyst supports described above using the system phoenix v|tome|x s (Phoenix, Germany). A voxel resolution of $2 \mu \mathrm{m}$ is used. 800 projections are acquired to allow the reconstruction of a $3 \mathrm{D}$ volume.

\subsubsection{Scanning Electron Microscopy}

The observation of the fracture surfaces of the samples is carried out with a SEM Supra 40 (Zeiss, Germany). The secondary electrons mode is used in order to observe the topographical contrast. Samples are glued on the sample holder with conductive double sided carbon adhesive tape and their sides are covered with conductive carbon paint. To avoid charge effects, a $2 \mathrm{~nm}$ thick layer of $\mathrm{Pt} / \mathrm{Pd}-\mathrm{metal}$ is deposited on samples surface.

\subsection{Strength Measurement}

\subsubsection{Crushing Strength}

The measurement of the crushing strength is carried out with a servo-hydraulic testing system Instron 8502 (High Wycombe, UK) as shown in Figure 1, associated with a $250 \mathrm{~N}$ load cell for the bimodal samples and a $5000 \mathrm{~N}$ load cell for the monomodal samples.

During the crushing of a perfectly cylindrical specimen the maximum tensile stress is located at the center of the sample, in the plane passing through both upper and lower contacting lines. It is given by (Timoshenko and Goodier, 1970):

$$
\sigma_{\max }=\frac{2 F}{\pi d l}
$$

where $F$ is the applied load at failure, $d$ and $l$ are the diameter and length of the specimen.

However, during crushing of cylindrical pellets, $\mathrm{Li}$ et al. (2000) observed that several fracture modes may happen due to their complex shape. To prevent multiple

TABLE 1

Characteristics of monomodal and bimodal catalyst supports made of highly porous gamma alumina

\begin{tabular}{l|c|c|c|c|c}
\hline Sample & Diameter $(\mathrm{mm})$ & $\begin{array}{c}\text { Total porous } \\
\text { volume }(\%)\end{array}$ & \multicolumn{2}{|c}{ Mean pore interconnection size (nm) } & $\begin{array}{c}\text { BET specific surface } \\
\text { area }\left(\mathrm{m}^{2} / \mathrm{g}\right)\end{array}$ \\
\hline Monomodal & $1.35 \pm 0.05$ & $66.5 \pm 0.5$ & Mesopores $(67 \%)$ & 8.4 & 325 \\
\hline \multirow{2}{*}{ Bimodal } & $1.45 \pm 0.05$ & $72.5 \pm 0.5$ & Mesopores (46\%) & 6.4 & 275 \\
\cline { 3 - 6 } & & & Macropores (27\%) & 675 \\
\hline
\end{tabular}



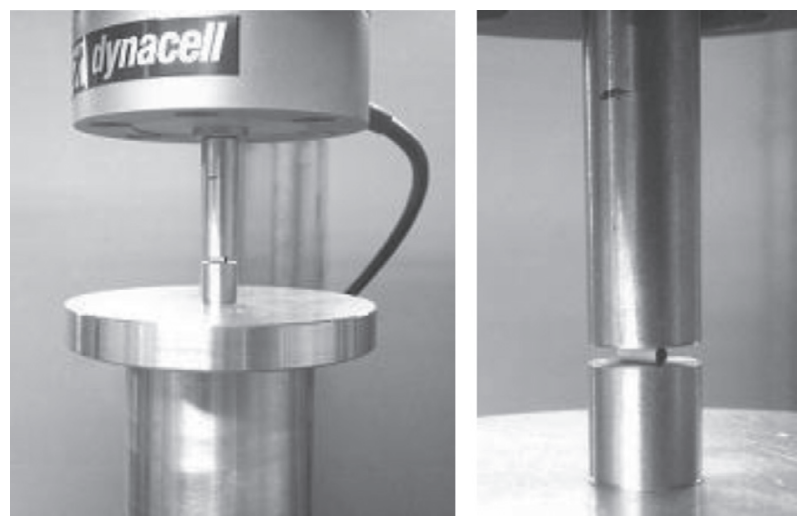

Figure 1

Side crushing strength test of a cylindrical support.
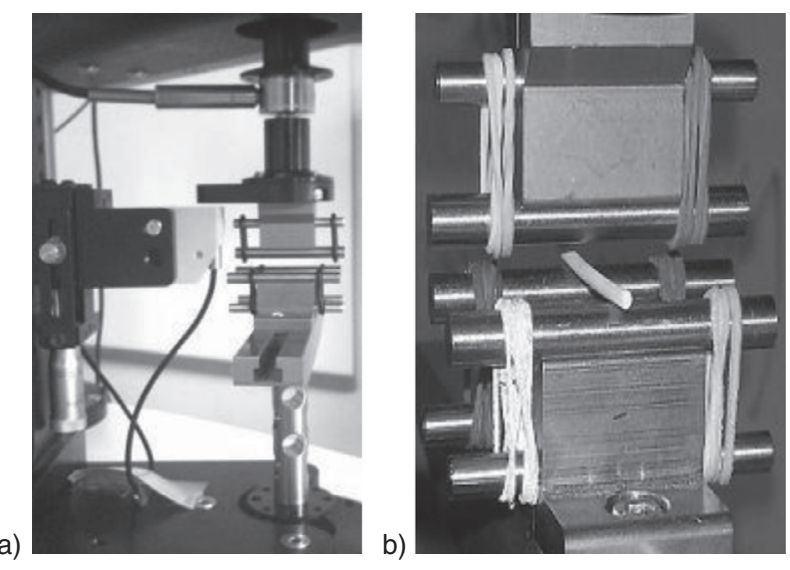

Figure 2

Three-point bending test: a) side view of the test device, and b) cylindrical extrudate under bending. fracture modes, the samples are chosen the closest to a cylindrical form, and with a length varying from 3 to $4 \mathrm{~mm}$. After measurement of their size, pellets are loaded at a rate of $0.05 \mathrm{~mm} / \mathrm{min}$ until failure. The load versus displacement curve is recorded, and regular unloadings are performed to observe the different fracture modes. The load at fracture of the pellet in two half-cylinders is normalized by the support's length and defined as the crushing strength. 41 samples of each type of supports (monomodal and bimodal) are tested.

\subsubsection{Bending Strength}

The bending strength is measured with a Bose ElectroForce ${ }^{\circledR} 3200$ test instrument (Prairie Valley, USA) associated with a $20 \mathrm{~N}$ load cell.

For a cylindrical specimen tested in three-point bending, the maximum tensile stress lies at the mid-distance between the two lower load points (Lemaitre and Chaboche, 2004). It can be calculated from:

$$
\sigma_{\max }=\frac{8 F L}{\pi d^{3}}
$$

where $L$ is the span between the lower load points. Furthermore, Young's modulus can be calculated according to (Lemaitre and Chaboche, 2004):

$$
E=\frac{4 L^{3}}{3 \pi d^{4}} \frac{F}{u}
$$

with $u$ the deflection of the sample.
The span between the two lower supporting rolls is set to $15 \mathrm{~mm}$. The samples chosen are longer than $15 \mathrm{~mm}$ and without apparent surface defects. After measurement of their diameter, pellets are loaded until fracture as presented in Figure 2. 30 samples of each type of supports (monodal and bimodal) are tested.

\subsubsection{Data Processing}

As previously mentioned, the brittle behavior of the catalyst supports requires a statistical approach to analyse the distribution of their strength. Weibull statistics is widely used to characterize the statistical variation in the fracture strength of brittle materials (ASTM C1239-00, 2005; Trustrum and Jayatilaka, 1983; Wu et al., 2002; Wu and Li, 2002), and it has been shown to be applicable to the characterization of solid catalysts strength (Li et al., 2000; Subero-Couroyer et al., 2003; Wu et al., 2006). Weibull statistics is based on the weakest link theory, which states that the most critical flaw in the material determines its strength.

Using Weibull's distribution, the probability of failure $P$ at a stress $\sigma$, for a homogeneous stress distribution, is given by (ASTM C1239-00, 2005; Weibull, 1951; Lu et al., 2004):

$$
P(\sigma, V)=1-\exp \left[-\frac{V}{V_{0}}\left(\frac{\sigma}{\sigma_{0}}\right)^{m}\right]
$$

where $V$ is the volume of a specimen, $V_{0}$ is the reference volume, $\sigma_{0}$ is the characteristic strength, and $m$ is the Weibull modulus. $m$ is a measure of the scatter of 
strength data (the lower $m$, the higher the dispersion of the data). For an inhomogeneous uniaxial stress state, Equation (3) can be written as (Lemaitre and Chaboche, 2004):

$$
P(\sigma, V)=1-\exp \left[-\frac{V_{e f f}}{V_{0}}\left(\frac{\sigma_{\max }}{\sigma_{0}}\right)^{m}\right]
$$

where the effective volume $V_{\text {eff }}$ is the volume of the sample weightened by the ratio of the local tensile stress to the maximum tensile stress $\sigma_{\max }$ at the power $m$. It is given by:

$$
V_{e f f}=\int_{V}\left(\frac{\sigma}{\sigma_{\max }}\right)^{m} d V
$$

The weighted linear regression is used for the estimation of Weibull parameters $m$ and $\sigma_{0}$ from the experimental distribution of strength (Bergman, 1986; Wu et al., 2001).

If two specimens with different sizes or geometries have the same probability of failure, Equation (4) gives:

$$
V_{e f f, 1} \sigma_{\max , 1}^{m}=V_{e f f, 2} \sigma_{\max , 2}^{m}
$$

which illustrates the size effect resulting from Weibull distribution: the larger the size of a specimen $V$ or the volume subjected to tensile stresses $V_{\text {eff }}$, the higher the probability of finding a critical flaw and the smaller the strength of the sample (Lawn, 1993; Bažant and Planas, 1998; Lu et al., 2004; Wachtman et al., 2009).

\subsubsection{Numerical Modeling}

To calculate the effective volume involved in crushing and bending tests, a numerical analysis of these tests is carried out using the finite element package ABAQUS ${ }^{\circledR}$. Because the stress state is poorly affected by the length of the support, the analysis is performed with a $2 \mathrm{D}$ plane strains model. Owing to two plane symmetries, only one quarter of the disc is analysed. The contact between the rigid platen and the deformable sample is defined frictionless. Symmetry conditions are set along the horizontal and vertical axis as presented in Figure 3a. A vertical displacement ramp is applied to the platen via a reference node.

The bending test analysis is carried out with a $3 \mathrm{D}$ model. As for the crushing test, symmetry of the system allows analysing only one quarter of the rod. The contact between the supporting rolls and the rod is defined frictionless. Symmetry conditions are set along the vertical plans as shown in Figure 3b. A vertical displacement ramp is applied to the upper roll via a reference node.
Finite element meshes and characteristics of the models are presented in Figure 3 and Table 2.

In each test, the material is considered as isotropic linear elastic and is characterized by a Young's modulus and a Poisson's ratio. Young's moduli have been previously determined experimentally by $3 \mathrm{~PB}$ tests and are set to 6.4 and 3.6 GPa for monomodal and bimodal extrudates respectively. Poisson's ratio is set to 0.22 for both materials, which corresponds to an analytical value obtained by Sanahuja et al. (2010) for highly porous

a)

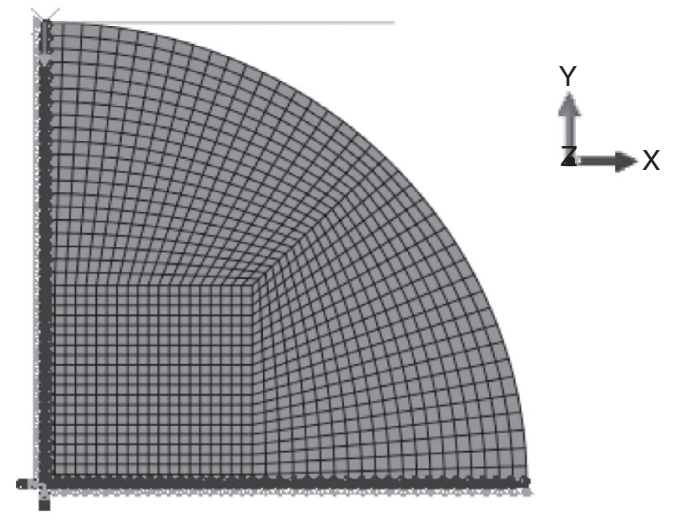

b)

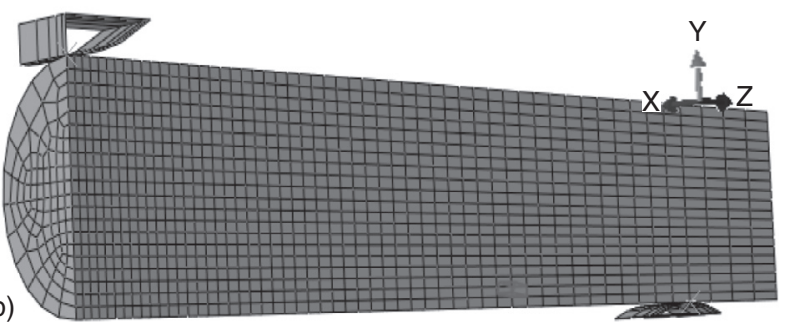

Figure 3

Finite element mesh employed: a) 2D-model of side crushing strength test and b) 3D-model of three-point bending test.

TABLE 2

Sizes of the numerical models used to simulate crushing and bending tests

\begin{tabular}{l|c|c}
\hline & $\begin{array}{c}\text { Crushing test } \\
\text { (2D-model) }\end{array}$ & $\begin{array}{c}\text { Three-Point } \\
\text { Bending } \\
\text { test (3D-model) }\end{array}$ \\
\hline Type of elements & $\begin{array}{c}\text { Linear plane } \\
\text { strain element } \\
\text { (4-node quadrangle) }\end{array}$ & $\begin{array}{c}\text { Linear element } \\
\text { (8-node brick) }\end{array}$ \\
\hline Number of elements & 1246 & 7784 \\
\hline Number of nodes & 1348 & 11235 \\
\hline
\end{tabular}


materials, independently of the Poisson's ratio of the solid matrix.

The effective volume $V_{\text {eff }}$ is calculated using Equation (5) and converted to a discretized sum:

$$
V_{\text {eff }}=\sum_{i}^{n}\left(\frac{\sigma_{I}^{i}}{\sigma_{\max }}\right)^{m} V_{i}
$$

The sum is performed with the $n$ integration points of the finite element model. $V_{i}$ is the volume associated to each integration point $i, \sigma_{I}^{i}$ is the maximum positive principal stress corresponding to each integration point $i$. If a material point is subjected to triaxial compression, $\sigma_{I}{ }^{i}$ is set to 0 . The numerical size effect (ratio between maximum tensile stresses) is calculated according to Equation (6), with the ratio between effective volumes obtained from the numerical analyses of crushing and bending tests.

\section{RESULTS}

\subsection{Samples Microstructure Observations}

Large defects are noted during sample observation in SEM and X-ray tomography (Fig. 4, 5). These can be less densified zones, surface defects, or axial cracks running along the extrudate length as it can be seen in Figure 4 . These defects originate from the extrusion process. Quantitatively speaking, axial cracks are present in large number in bimodal supports structure (Fig. 4c, d), while they are only present in few monomodal extrudates (Fig. 4a, b). They are mainly located in the bulk of the samples. Moreover, monomodal supports are characterized by larger surface defects as compared to bimodal supports (Fig. 4).

\subsection{Crushing Strength}

During the crushing test, two different fracture modes are observed. One is a fracture due to radial tension stresses, where the cylinders fracture into two half pellets along the plane passing through the two contacting lines (Fig. 6a). This fracture mode is expected to happen in the Crushing Configuration (CC), for which the calculation of the maximum tensile stress is known and explained above (Eq. 1).

The other one is a fracture due to a Bending Configuration (BC) inducing axial tensile stresses. The supports are snapped into two short cylinders (Fig. 6b). This BC originates from the irregular geometry of the extrudates: the curvature of the supports induces discontinuous

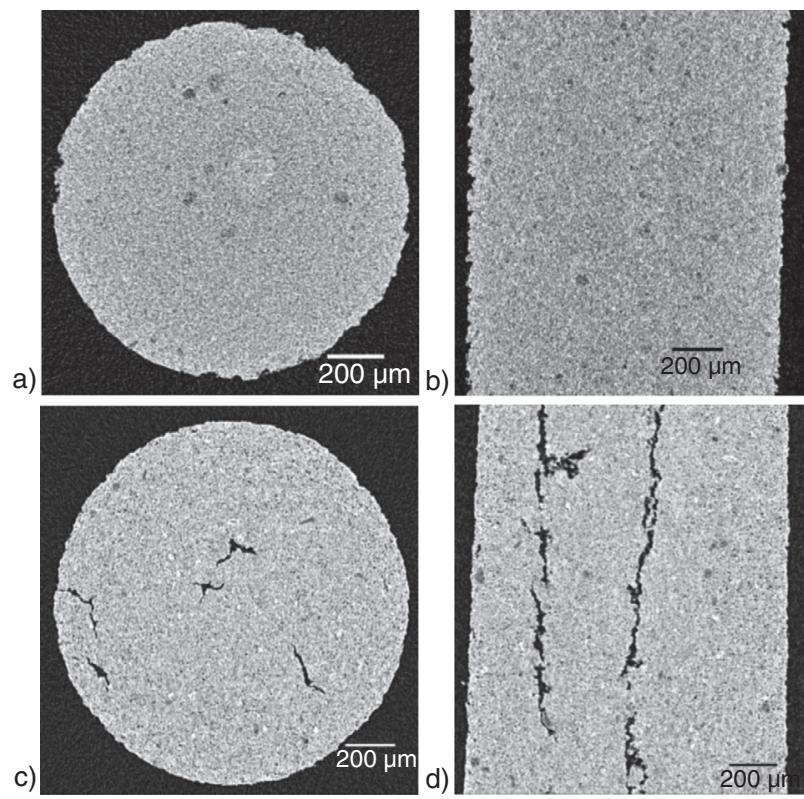

Figure 4

X-Ray tomography observation of horizontal and vertical cuts of a,b) a monomodal support and c,d) a bimodal support.

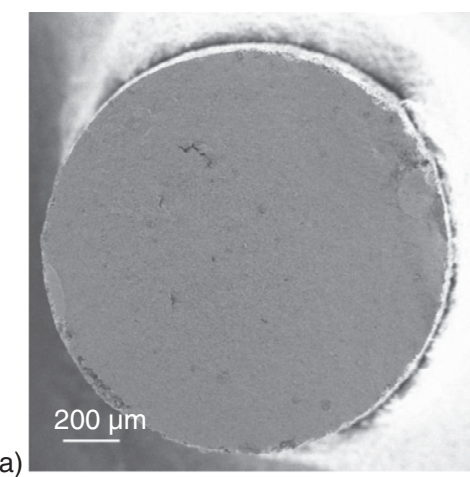

b)

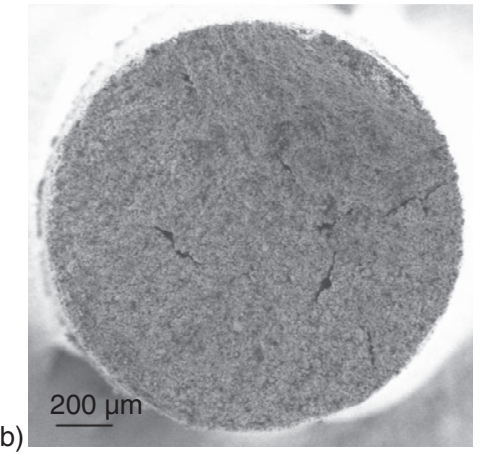

Figure 5

SEM micrographs (magnitude $50 \times$ ) of fracture surfaces of a) monomodal and b) bimodal supports respectively after bending tests. 
a)

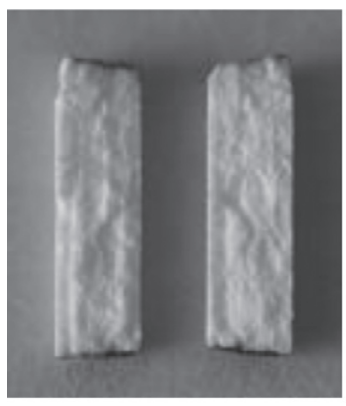

b)

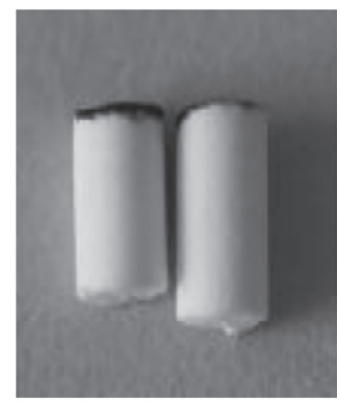

c)

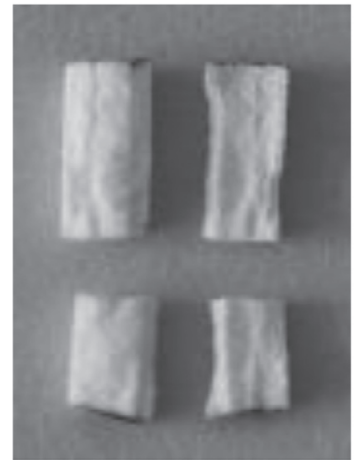

Figure 6

Fragments of bimodal supports (1.4 mm of diameter) after crushing tests. Fracture under $\mathrm{CC}$ a), under $\mathrm{BC}$ b) and involving both configurations $\mathrm{c}$ ).

contact lines with the platens, resulting in a shearing and bending mode.

In most cases, both fractures happen during the test. First, the sample fractures under BC, splitting into two short cylinders. Both cylinders are then reloaded with the same load per unit length until fracture under CC. The resulting sample is fractured into four half-cylinders as presented in Figure 6c.

Figure 7 presents the different load versus displacement curves obtained during crushing of monomodal supports depending on the fracture modes involved. For bimodal supports, the curves are alike. Figure $7 \mathrm{~b}$ shows the curve obtained when the two fracture modes $\mathrm{BC}$ and $\mathrm{CC}$ are activated. At low loads, we observe a small load drop that corresponds to BC fracture. Then, an increase of the curve slope characterizes the setting of the CC, which is stiffer than the BC. Finally, a large load drop is observed at higher loads, which corresponds to the quasi-simultaneous fracture of the two small cylinders under CC.

Figure 8 presents the distributions in fracture loads recorded during crushing of the samples. The associated fracture mode is noted. Fractures under BC happen at low loads for most of the samples $(80 \%$ of bimodal
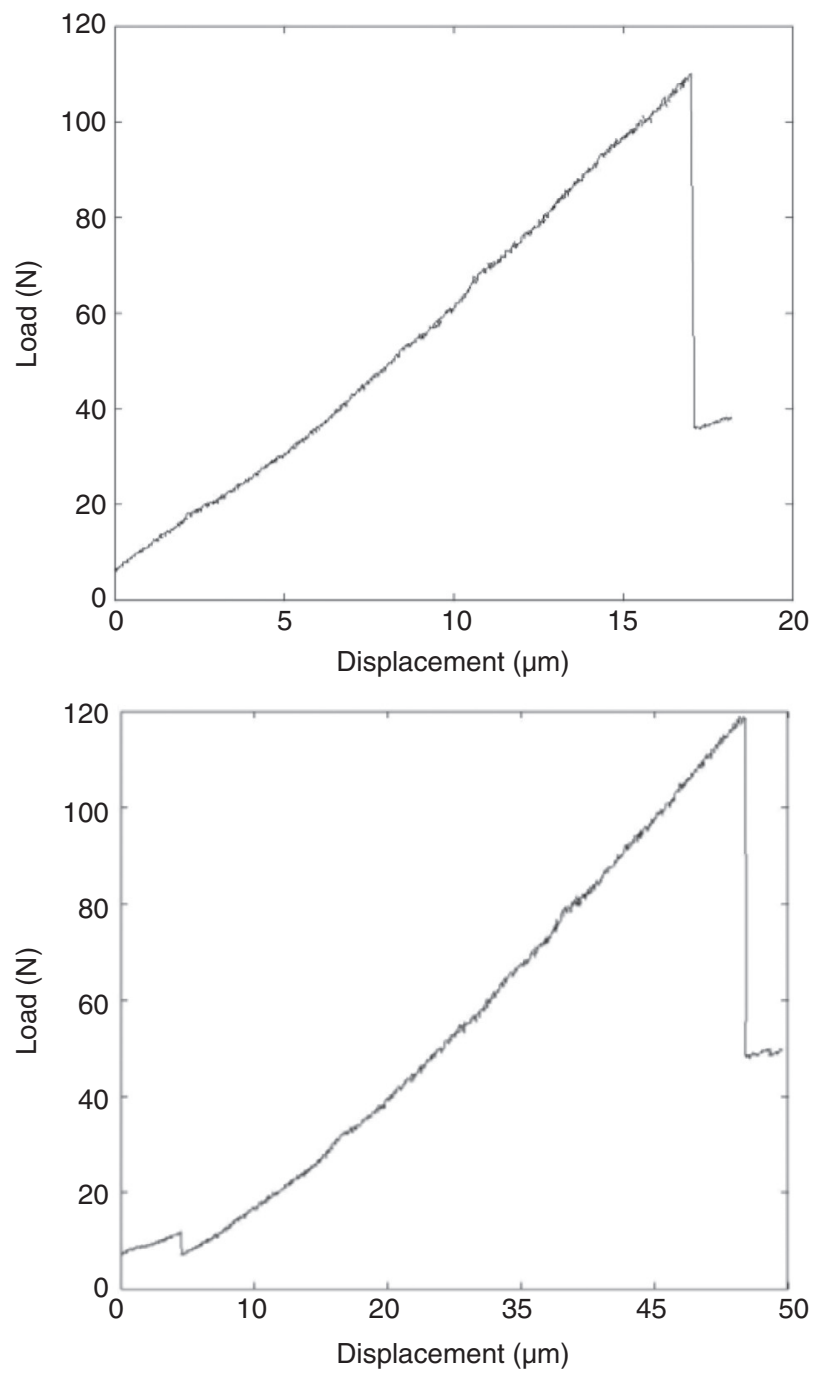

Figure 7

Load versus displacement curves obtained during crushing of monomodal supports. a) Fracture under crushing configuration at $110 \mathrm{~N}$; b) fracture under bending configuration at $12 \mathrm{~N}$ followed by a fracture under crushing configuration at $120 \mathrm{~N}$.

supports and $100 \%$ of monomodal supports), while fractures under $\mathrm{CC}$ happen at higher loads. If no distinction is made in fracture modes, this induces a large scatter of the strength data. Nevertheless, it is to be noted that Equation (1) is only valid when fracture happens under radial tensile stresses (CC). In this context, the loads corresponding to fractures under $\mathrm{BC}$ are removed to obtain the distribution corresponding to fractures under $\mathrm{CC}$ only, and calculate the corresponding maximum tensile stresses.

For the two types of supports, Weibull parameters obtained after statistical analysis of the results are 

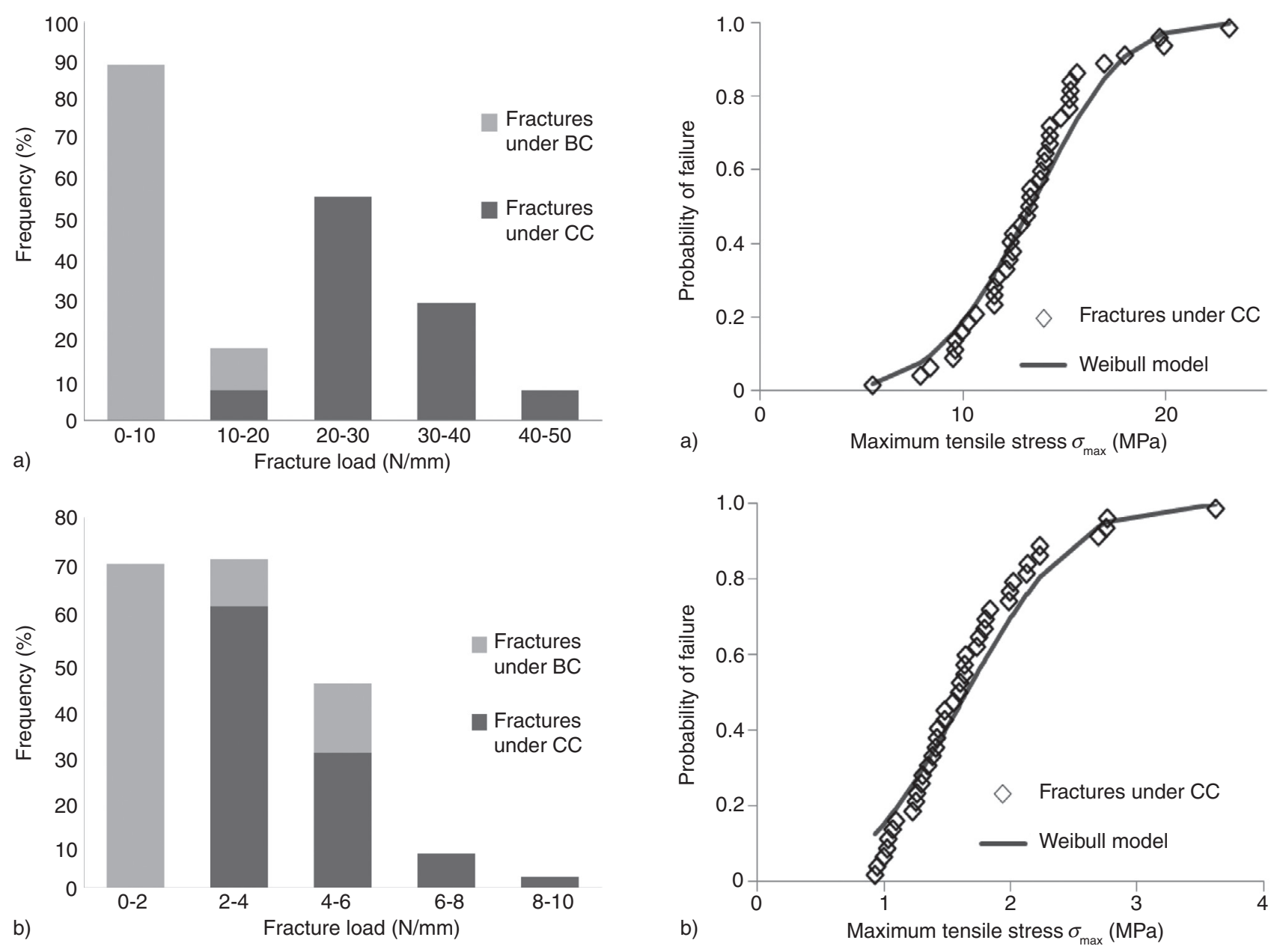

Figure 8

Fracture load distributions obtained after crushing of the samples depending on the fracture mode for a) monomodal and b) bimodal supports.

Figure 9

Fitting of the Weibull model to the experimental crushing data for a) monomodal and b) bimodal supports. Only fractures under $\mathrm{CC}$ are considered.

TABLE 3

Maximum tensile stress at fracture and Weibull parameters obtained after statistical analysis of the crushing data

\begin{tabular}{l|c|c|c|c|c}
\hline \multirow{2}{*}{ Sample } & \multicolumn{2}{|c|}{$\sigma_{\max }(\mathrm{MPa})$} & $m$ & \multicolumn{2}{c}{$\sigma_{0}(\mathrm{MPa})$} \\
\cline { 2 - 6 } & Mean value & Standard deviation & & $R^{2}$ \\
\hline Monomodal & 13.2 & 3.3 & 4.1 & 15 & 0.98 \\
\hline Bimodal & 1.7 & 0.6 & 2.9 & 2 & 0.95 \\
\hline
\end{tabular}

presented in Table 3. A comparison between Weibull distribution and experimental data is shown in Figure 9. Weibull modulus is higher for monomodal supports, which means a lower dispersion of the results than for bimodal supports. Furthermore, Weibull model seems to fit better the experimental data for monomodal supports as suggests the higher correlation coefficient $R^{2}$. It can also be observed in Figure 9. Moreover, the maximum tensile stress at fracture is higher for monomodal supports.

\subsection{Bending Strength}

During the 3PB tests, all the supports fracture under the upper load point, resulting in two short cylinders 
TABLE 4

Maximum tensile stress at fracture and Weibull parameters obtained after statistical analysis of the bending data

\begin{tabular}{l|c|c|c|c|c}
\hline \multirow{2}{*}{ Sample } & \multicolumn{2}{|c|}{$\sigma_{\max }(\mathrm{MPa})$} & \multirow{2}{*}{$\sigma_{0}(\mathrm{MPa})$} & \multicolumn{2}{c}{$R^{2}$} \\
\cline { 2 - 6 } & Mean value & Standard deviation & & 18 & 0.97 \\
\hline Monomodal & 17.1 & 2.6 & 7.5 & 9 & 0.95 \\
\hline Bimodal & 8.1 & 1.1 & 8.9 & 9 \\
\hline
\end{tabular}
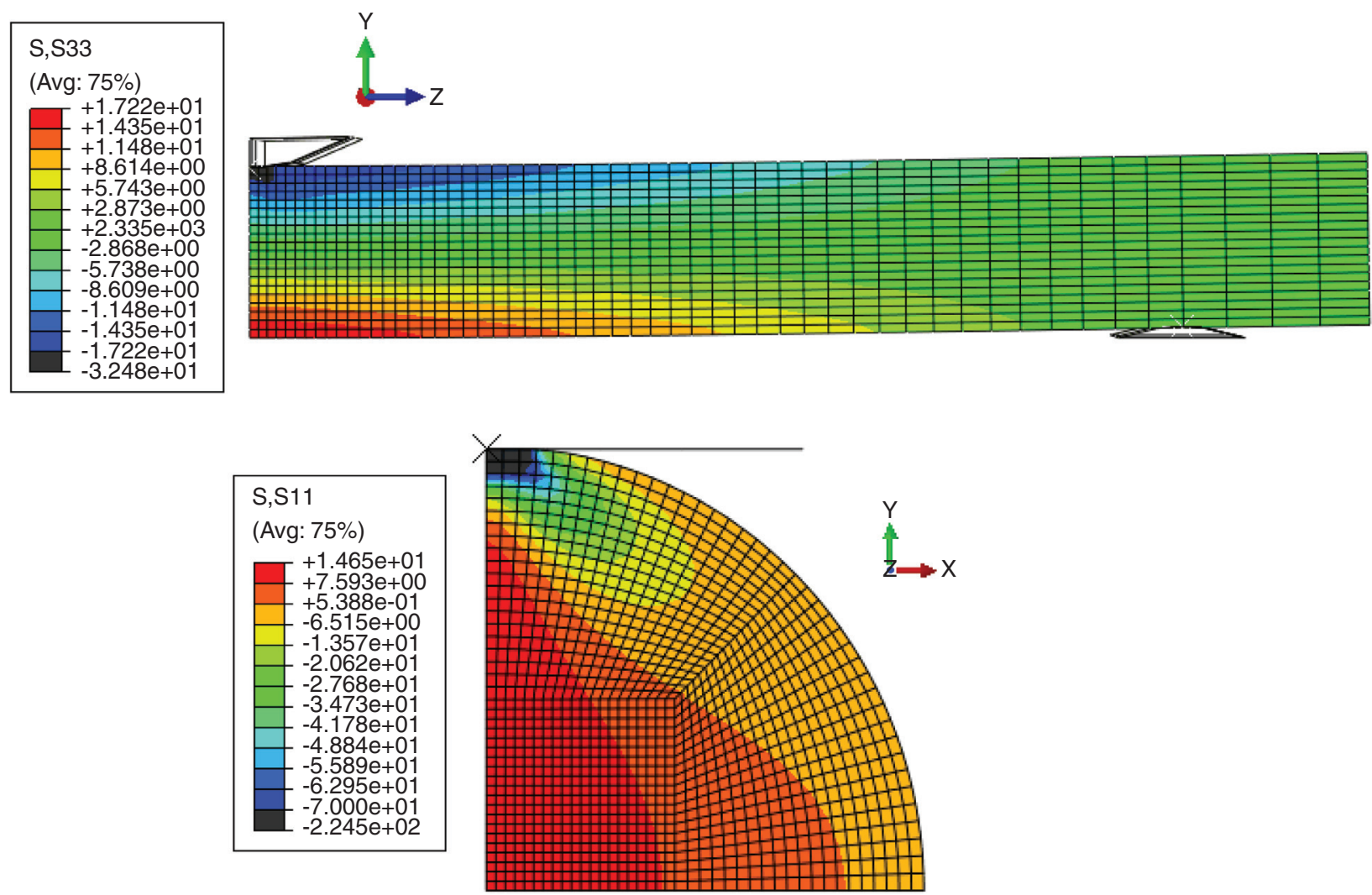

Figure 10

Distributions of the stresses inducing the fracture of the supports during the different tests: a) axial stresses $\sigma_{z z}$ (S33) distribution obtained under bending test simulation at $5 \mathrm{~N}$; b) radial stresses $\sigma_{x x}(\mathrm{~S} 11)$ distribution obtained under crushing test simulation at $140 \mathrm{~N}$. The values of the stresses are given in MPa.

of similar length. The results are presented in Table 4. The maximum tensile stress at fracture is twice higher for monomodal supports than for bimodal supports. Weibull modulus is slightly higher for bimodal supports than for monomodal supports.

When comparing bending data with crushing data, the mean value of the maximum tensile stress $\sigma_{\max }$ at fracture is found to be higher when measured with the bending test. The experimental ratios $\sigma_{\text {max-bending/ }}$ $\sigma_{\text {max-crushing }}$ is equal to 1.3 for monomodal supports and to 4.9 for bimodal supports.

Moreover, Weibull modulus is higher for bending data, implying a lower dispersion of the strength, thus a higher reliability of the results. It can be noted that Weibull statistics is well suited to characterize the strength distribution of catalyst supports for both tests (as indicated by a correlation coefficient $R^{2}$ higher than 0.94), despite their high porous volume.

\subsection{Numerical Modeling}

Figure 10 shows the stress distributions obtained within the supports after numerical simulation of the bending and crushing tests. The elements colored in red are those subjected to the highest tensile stresses. These are parallel to the support axis for bending 
TABLE 5

Ratios between volumes and maximum tensile stresses obtained with the numerical analysis of crushing and bending tests - comparison with the experimental ratio

\begin{tabular}{l|c|c|c}
\hline Samples & $\frac{V_{\text {eff }- \text { crushing }}}{V_{\text {eff } \text {-bending }} \text { numerical }}$ & $\frac{\sigma_{\text {max } \text {-bending }}}{\sigma_{\text {max }- \text { crushing }} \text { Eq. 6) }}$ & $\frac{\sigma_{\text {max }- \text { bending }}}{\sigma_{\text {max }- \text { crushing }} \text { experimental }}$ \\
\hline Monomodal & 4.2 & 1.2 & 1.3 \\
\hline Bimodal & 4.8 & 1.2 & 4.9 \\
\hline
\end{tabular}

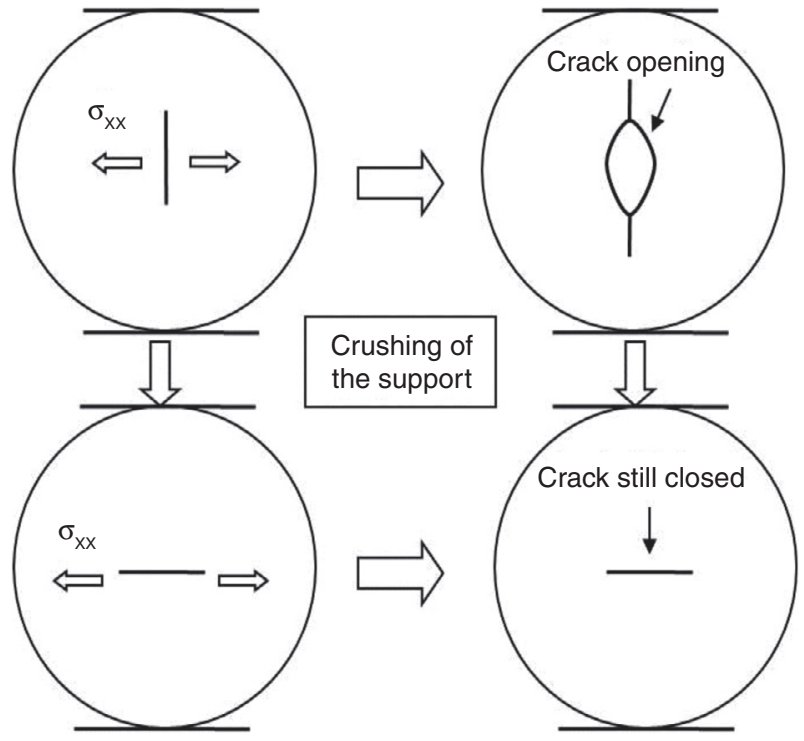

Figure 11

Diagram of radial tensile stresses $\sigma_{\mathrm{xx}}$ inducing a) or not b) opening of axial cracks during crushing of the support.

test, and perpendicular to the support axis for crushing test.

As the crushing model is a 2D model, the effective volume $V_{\text {eff }}$ calculated is multiplied by the sample characteristic length of the supports tested in crushing ( $3.5 \mathrm{~mm})$. This allows one to compare it to the bending model (3D-model). The values are presented in Table 5. Under crushing, $V_{\text {eff }}$ is approximately 4 and 5 times higher for monomodal and bimodal supports respectively, than under bending. The difference between the two types of supports is due to the slightly higher diameter of bimodal supports.

The stress ratios due to the size effect are calculated from the volume ratios with Equation (6). The Weibull moduli obtained from the bending data are used, as they are considered as more reliable than from the crushing data. The stress ratio calculated numerically is close to the experimental one for monomodal supports. For bimodal supports, however, the numerical stress ratio is much smaller than the experimental one.

\section{DISCUSSION}

The analysis of the crushing and bending data shows that the maximum tensile stress of the supports is lower when measured in crushing than when measured in three-point bending $(T a b .3,4)$. On one hand, this comes from the difference of volume of the sample subjected to tensile stresses. This volume is more than four times higher during crushing than during bending of a cylindrical rod. According to the theory of brittle fracture, the probability of finding a critical flaw is higher during crushing, inducing a lower tensile strength (Lawn, 1993; Bažant and Planas, 1998; Lu et al., 2004; Wachtman et al., 2009). As it can be seen in Table 5, this Weibull size effect can explain the experimental strengths difference between crushing and bending tests for monomodal supports but not for bimodal supports. These latters show an experimental strength's difference four times larger than the one due to Weibull size effect.

On the other hand, the effect of bulk defects can explain the lower strength measured in crushing. The X-ray tomography and SEM observations showed the presence of a lot of axial cracks within bimodal supports. Only a few monomodal supports contain axial cracks. As it can be seen in Figure 10, axial cracks are parallel to maximum tensile stresses during the 3PB test. Moreover, Figure 4 shows that most of the cracks are not located near the surface of the support. This results in a limited influence of the cracks during the 3PB test. On the contrary, during the crushing test, these cracks are located in the volume subjected to tensile stresses, and perpendicular to those stresses. Depending on the angle formed between the axial cracks and the tensile stresses, these latters can provoke the opening and subsequent propagation of the cracks (Fig. 11). This results in a lower tensile strength of the bimodal supports. Moreover, this variation of cracks orientation and location induces a higher scatter of the crushing data for bimodal support (Tab. 3). 
While comparing the scatter of the strength data, it is found to be larger for the crushing data than for the bending data (Weibull moduli in Tab. 3 and 4). This can be related to the sample's stress state during the tests: during crushing, the inner volume is subjected to tensile stresses and fracture can start all along the support's length depending on the location of the most critical volume defect; during bending, the fracture is always favored at the surface under the upper load point and the defects loaded are surface defects. As no large defects are present at the surface of both monomodal and bimodal supports (Fig. 4), the bending test gives a tensile strength more representative of the intrinsic mechanical resistance of their microstructure. Thus, the twice higher tensile strength of monomodal supports measured in bending is due to a more resistant microstructure. Indeed, bimodal supports exhibit a higher porous volume and possess a macroporosity (pore size higher than $0.5 \mu \mathrm{m}$ ) that is not present within monomodal supports (Tab. 1).

\section{CONCLUSION}

- The side crushing strength test is a common test used to characterize the mechanical properties of catalyst supports. While it is automatized in industry to test usual materials, it is necessary to analyze and sort out the different fracture modes involved during the test to obtain a correct distribution of the data. This analysis is also necessary to correctly compare and classify catalyst supports;

- the maximum tensile stress measured in crushing is lower than when measured in bending. Weibull size effect explains this difference for monomodal supports. For the bimodal supports tested in this study, the higher difference is due to the axial cracks present within the supports and directly loaded during crushing. The formation of a part of these cracks could be avoided by extruding the supports under vacuum. This operation could improve the mechanical properties of catalyst supports;

- the scatter of the data is higher with the crushing test than with the bending test because of a different type of defects solicited. Surface defects are solicited during bending while volume defects (cracks) are solicited during crushing;

- tensile strength of bimodal supports is lower than that of monomodal supports in crushing and bending. First, bulk defects (axial cracks) decrease the strength of bimodal supports during crushing. Second, the microstructure of bimodal supports is weaker because of their higher porous volume and the presence of macropores that are not present in monomodal supports.

\section{ACKNOWLEDGMENTS}

The authors gratefully acknowledge J. Adrien for the help on X-Ray Tomography at INSA-Lyon (Villeurbanne, France), and $\mathrm{H}$. Marmet for realizing the SEM observations at IFP Energies nouvelles (Solaize, France).

\section{REFERENCES}

Andrew S.P.S. (1981) Theory and practice of the formulation of heterogeneous catalysts, Chemical Engineering Science 36, 9, 1431-1445.

ASTM C1239-00 (2005) Standard practice for reporting uniaxial strength data and estimating Weibull distribution parameters for advanced ceramics, ASTM International, West Conshohocken, PA.

ASTM D4179-01 (2001) Standard test method for single pellet crush strength of formed catalyst shapes, ASTM International.

ASTM D6175-03 (2003) Standard test method for radial crush strength of extruded catalyst and catalyst carrier particles, ASTM International, West Conshohocken, PA.

Bažant Z.P., Planas J. (1998) Fracture and Size Effect in Concrete and Other Quasibrittle Materials, CRC Press, Boca Raton.

Beaver E.R. (1975) Mechanical testing of catalysts, Chemical Engineering Progress 71, 1, 44-45.

Bergman B. (1986) Estimation of Weibull parameters using a weight function, Journal of Materials Science 5, 6, 611-614.

Denny P.J., Twigg M.V. (1980) Factor determining the life of industrial heterogeneous catalysts, Studies in Surface Science and Catalysis 6, 577-599.

Euzen P., Raybaud P., Krokidis X., Toulhoat H., Le Loarer J. L., Jolivet J.P., Froidefond C. (2002) Chapter 4.7.2. Alumina, in Handbook of Porous Solids, Schüth F., Sing K.S.W., Weitkamp J. (eds),Wiley-VCH Verlag GmbH, Weinheim.

Fulton J.W. (1986) Testing the catalyst, Chemical Engineering Journal 93, 19, 71-77.

Gallei E., Schwab E. (1999) Development of technical catalysts, Catalysis Today 51, 3-4, 535-546.

Griffith A.A. (1921) The phenomena of rupture and flow in solid, Philosophical Transactions of the Royal Society of London A 221, 163-175.

Kanninen M.F., Popelar C.H. (1985) Advanced Fracture Mechanics, Oxford University Press, New York.

Lawn B.R. (1993) Fracture of Brittle Solids - Second Edition, Cambridge University Press, Cambridge.

Lemaitre J., Chaboche J.L. (2004) Mécanique des milieux continus, Dunod, $2^{\mathrm{e}}$ éd, Paris.

Li Y.D., Chang L., Li Z. (1989) Measurement methods and reliability analyses for mechanical strength of solid oxide catalysts, Journal of Tianjin University 3, 9-17.

Li Y.D., Li X.M., Chang L., Wu D.H., Fang Z.P., Shi Y.H. (1999) Understandings on the scattering property of the mechanical strength data of solid catalysts: a statistical analysis of iron-based high-temperature shift catalysts, Catalysis Today 51, 1, 73-84. 
Li Y.D., Wu D.F., Zhang J.P., Chang L., Wu D.H., Fang Z.P., Shi Y.H. (2000) Measurement and statistics of single pellet mechanical strength of differently shaped catalysts, Powder Technology 113, 1-2, 176-184.

Li Y., Wu D., Lin Y.S. (2004) Mechanical strength and reliability of solid catalysts, China Particuology 2, 2, 53-62.

Lu C., Danzer R., Fischer F.D. (2004) Scaling of fracture strength in $\mathrm{ZnO}$ : Effects of pore/grain-size interaction and porosity, Journal of European Ceramic Society 24, 14, 3643-3651.

Standard National of China GB-3635-83 (1983) Determination of granular crush-strength for fertilizer catalyst, molecular sieve and adsorbent, National Standard Bureau, Beijing.

National Standard of China GB-10505.1-89 (1989) Determination of granular crush-strength for molecular sieve $3 A$, National Standard Bureau, Beijing.

Richardson J.T. (1989) Principles of Catalyst Development, Plenum Press, New York.

Sanahuja J., Dormieux L., Meille S., Hellmich C., Fritsch A. (2010) Micromechanical Explanation of Elasticity and Strength of Gypsum: From Elongated Anisotropic Crystals to Isotropic Porous Polycrystals, Journal of Engineering Mechanics 136, 2, 239-253.

Subero-Couroyer C., Ghadiri M., Brunard N., Kolenda F. (2003) Weibull analysis of quasi-static crushing strength of catalyst particles, Chemical Engineering Research and Design 81, 8, 953-962.

Timoshenko S.P., Goodier J.N. (1970) Theory of elasticity, 3rd edn., McGraw-Hill, New York.

Trustrum K., Jayatilaka A.D.S. (1983) Applicability of Weibull analysis for brittle materials, Journal of Materials Science 18, 9, 2765-2770.

Wachtman J.B., Cannon W.R., Matthewson M.J. (2009) Mechanical Properties of Ceramics, John Wiley \& Sons, Inc., New York.
Weibull W. (1951) A statistical distribution function of wide applicability, Journal of Applied Mechanics 18, 3, 293-297.

Wu D.F., Li Y.D. (2002) Effects of the impregnating and drying process factors on the mechanical properties of a PCoMo/ $\mathrm{Al}_{2} \mathrm{O}_{3}$ hydrotreating catalyst, Studies in Surface Science and Catalysis 143, 101-109.

Wu D.F., Li Y., Zhang J., Chang L., Wu D., Fang Z., Shi Y. (2001) Effects of the number of testing specimens and the estimation methods on the Weibull parameters of solid catalysts, Chemical Engineering Science 56, 24, 7035-7044.

Wu D.F., Li Y.D., Shi Y.H., Fang Z.P., Wu D.H., Chang L. (2002) Effects of the calcination conditions on the mechanical properties of a $\mathrm{PCoMo} / \mathrm{Al} 2 \mathrm{O} 3$ hydrotreating catalyst, Chemical Engineering Science 57, 17, 3495-3504.

Wu D.F., Song L.Y., Zhang B.Q., Li Y.D. (2003) Effect of the mechanical failure of catalyst pellets on the pressure drop of a reactor, Chemical Engineering Science 58 , 17, 3995-4004.

Wu D.F., Zhou J.C., Li Y.D. (2006) Unbiased estimation of Weibull parameters with the linear regression method, Journal of European Ceramic Society 26, 7, 1099-1105.

Wu D.F., Zhou J., Li Y. (2007) Mechanical Strength of Solid Catalysts: Recent Developments and Future Prospects, AIChE Journal 53, 10, 2618-2629.

Cite this article as: D. Staub, S. Meille, V. Le Corre, J. Chevalier and L. Rouleau (2015). Revisiting the Side Crushing Test Using the Three-Point Bending Test for the Strength Measurement of Catalyst Supports, Oil Gas Sci. Technol 70, 3, 475-486. 